\title{
A NATUREZA COMO ESPAÇO EDUCACIONAL: OPORTUNIDADES PARA A INFÂNCIA
}

\author{
Renata Pavesi Cocito
}

Universidade Estadual Paulista - UNESP, Programa de Pós-graduação em Educação, Presidente Prudente, SP. E-mail: renatapavesi@hotmail.com

\section{RESUMO:}

O artigo apresenta a natureza concebida como um espaço educacional no âmbito da Educação Infantil, rico em possibilidades e em oportunidades para as crianças vivenciarem a infância. A qualificação do olhar pedagógico é considerada fundamental, pois possibilita enxergar oportunidades criativas e motivadoras para as crianças em diferentes espaços. Algumas experiências que envolvem criança e natureza são expostas para suscitar reflexões acerca dos fazeres pedagógicos cotidianos na Educação Infantil. Evidencia o brincar como uma expressão marcante e indissociável da infância, que pode ser desenvolvido em meio à natureza, com poucos recursos e em relação constante com os pares. A natureza precisa estar presente na organização espacial e/ou no cotidiano das instituições, considerando a realidade e as possibilidades de cada contexto, pois é compreendida como um espaço potente para o desenvolvimento infantil.

Palavras - chave: natureza - espaço educacional - Educação Infantil - brincar - desenvolvimento infantil

\section{NATURE AS AN EDUCATIONAL AREA FOR CHILDHOOD}

\section{ABSTRACT:}

This article presents the nature conceived as an educational area in the framework of early childhood education (pre-school), rich in possibilities and opportunities for children to experience childhood. The qualification of the pedagogical look is considered vital since it enables seeing creative and motivating opportunities for children in different areas. Some experiments which involves children and nature are exposed to arouse reflections about the daily chores teaching in kindergarten. It highlights "playing" as a remarkable and inseparable expression of childhood that can be developed in nature surrounds, with few resources and constant relationship with their peers. Nature must be included in the spatial organization and/or on the daily life of institutions, considering the reality and possibilities of each context, whereas it is understood as a powerful space for child development.

Keyword: nature - educational space - Early Childhood Education - play - child development 


\section{INTRODUÇÃO}

O espaço educacional, estruturado nos prédios escolares, atende as necessidades e características relacionadas à infraestrutura para instituições de Educação Infantil como convencionalmente conhecemos. Como espaço educacional entende-se aquele que possui estrutura e organização destinada à realização de ações, planejadas e mediadas pelo adulto, cujo foco esta no desenvolvimento e na educação básica de crianças.

A Educação Infantil, primeira etapa da educação básica, engloba os fazeres pedagógicos de crianças de 0 à 5 anos e 11 meses de idade, nas modalidades creche ( 0 a 3 anos e 11 meses) e préescola (4 anos a 5 anos e 11 meses de idade). A educação de crianças nesta faixa etária comumente ocorre em espaços com características muito peculiares, através da leitura da mensagem visual do espaço é possível identificarmos que aquele é um espaço destinado à Educação Infantil: presença de cores alegres e vibrantes, figuras e desenhos animados, parque infantil, tanque de areia, brinquedos e outros elementos característicos da infância.

O brincar é uma forma de expressão da criança que pode acontecer em qualquer local, com diferentes materiais e objetos. Alguns espaços podem não se configurar de forma convencional e não nos oferecer "pistas" claras de que é um espaço com potencialidades pedagógicas e promotoras do desenvolvimento infantil. Por isso, colocamos a qualificação do olhar pedagógico em relação aos espaços destinados às crianças, como fundamental: um olhar para além do óbvio e do costumeiro, que possibilite enxergar oportunidades criativas e motivadoras para as crianças em diferentes espaços. Desta forma este artigo tem como ponto de reflexão a natureza como espaço educacional. Esta possibilidade de atribuirmos à outros espaços, especialmente a natureza, o caráter educativo e de aprendizagem é defendida por Barbieri:

Todos os lugares são lugares de aprender. Cidades, florestas, quintais, territórios a serem investigados, com árvores, rios, clareiras, praças, praias. A natureza é um manancial de possibilidades para a formação estética, não só para as crianças, como para todos os seres humanos (BARBIERI, 2012, p.115).

De posse desta percepção, trazemos algumas experiências, que podemos considerar inovadoras pelo simples fato de resgatar nossas raízes como seres humanos, seres da Terra e nossa conexão direta com o mundo. Direcionar o olhar para a natureza e identificar nela possibilidades de ação educativa é uma forma de ressignificarmos nosso fazer docente e oferecer às crianças oportunidades de se viver a infância além dos muros e das paredes das escolas, ampliando sua relação com o mundo.

\section{METODOLOGIA}

Para compreendermos a natureza como espaço educacional, apresentamos a proposta de "Escolas da Floresta" ou "Forest School" que são caracterizadas pela a ausência do espaço físico construído nos moldes tradicionais e pelo contato direto e intenso com a natureza. Podemos encontrar esse tipo de organização na Suíça, Escócia, Inglaterra, Noruega, Dinamarca, Alemanha, Japão e Estados Unidos, por exemplo.

Nessas instituições as atividades pedagógicas e de cunho educativo acontecem em meio aos ambientes naturais, ou seja, espaços não estruturados e planejados com a intencionalidade de ser um espaço especificamente para o uso das crianças. $O$ espaço é descoberto e reinventado pelo grupo de crianças e adultos, sua estruturação e a utilização dos materiais são feita em harmonia com a natureza. É da natureza que resgatam possiblidades de brincadeiras, de interação com o espaço e com os elementos que o compõem, as crianças se integram aos espaços naturais.

Ao resgatar a origem dessas instituições itinerantes espalhadas pelos países do norte europeu, Carruthers (2010) relata que na Inglaterra originaram-se em 1995 decorrente de uma 
visita que os alunos do curso de formação para a Educação Infantil de uma instituição inglesa fizeram à Dinamarca. Observaram que as crianças ficavam predominantemente ao ar livre e que estar inseridas no espaço interno era a exceção, diferentemente do que ocorre na instituições tradicionais. Este fato despertou a atenção desses profissionais que se aperfeiçoaram e se capacitaram para poderem desbravar a floresta junto com as crianças. (Carruthers, 2010, p.195 196)

Existem documentários e notícias sobre diversas experiências de "Escolas da florestas", como: "Kids gone wild: Denmark's Forest kindergartens" da Dinamarca, "Nature Kindergarten: frances Krusekopf" da França, "Maruntabo - The forest kindergartens" do Japão e o "School's Out: Lessons From a Forest Kindergarden " da Suiça. Para o artigo vamos usar a descrição do espaço e de sua utilização com base na experiência retratada no documentário suíço.

A experiência suíça é retratada em um documentário com duração de pouco mais de 6 minutos onde mostram a rotina das crianças que frequentam uma instituição ao ar livre. Um grupo de aproximadamente 15 crianças é acompanhado por 3 adultos, as crianças utilizam transporte público para chegar a zona rural. No caminho para o local onde ficarão instalados, caminham em meio às propriedades e criações de animais.

A instalação que utilizam fica localizada em uma área arborizada, o chão é de terra batida, a cobertura é feita por uma grande lona preta, o entorno é circundado por uma barreira/parede de galhos empilhados, troncos de árvores cortados se transformaram em bancos, ao centro tem uma estrutura de pedras para produzirem fogo/fazer um fogueira.

$\mathrm{O}$ abrigo utilizado pelos educadores e crianças funciona como uma base para educadoras e crianças. Tuan (2012, p.163) fala sobre a capacidade envolvente que a natureza pode exercer sobre os sujeitos e afirma "o próprio meio ambiente natural pode produzir uma sensação de abrigo (...)". O banheiro é de estrutura semelhante ao abrigo, em proporção menor, com um local para poderem evacuar. Ambas as estruturas são edificadas de forma rústica, não há requintes no acabamento.

Carruthers (2010) ao falar sobre a estrutura física das experiências ao ar livre de instituições norueguesas coloca:

Nesses jardins de infância noruegueses não existem muitos equipamentos ou brinquedos nas áreas externas, mas todos os dias as crianças ficam em áreas com rios, regatos e vegetação. A natureza desempenha um papel muito importante na cultura norueguesa - é um modo de vida. (CARRUTHERS, 2010, p.195)

Em meio à mata, as crianças utilizam vários balanços de tamanhos variados espalhados pelo entorno, brincam nos riachos, fazem fogueiras e são orientadas para fazer o uso do fogo de forma correta e segura, utilizam facas/canivetes, pregos, martelos e pequenos serrotes para produzir artefatos e intervir em outros elementos que necessitam para incrementar suas brincadeiras e construções, brincam com terra e na terra, usam cordas, pedras e gravetos e outros elementos da natureza para compor os momentos de brincar, sobem em árvores.

A natureza trás em si desafios físicos e estéticos que mobilizam as crianças a se aventurar. A lama, a areia as pedras, seus formatos e cores, seus pesos, temperaturas; as plantas, suas folhas, sementes, troncos e talos, raízes com diferentes texturas, cheiros, cores e tamanhos; e os animais que habitam esses lugares: os insetos com seus ruídos peculiares, suas cores e formatos; os diferentes relevos, as topografias: rios montes, barrancos, planícies. Enfim, um universo de possibilidades a serem observadas e investigadas, a serem brincadas, que nos levam ao sentimento de

\footnotetext{
${ }^{1}$ Escola ao ar livre: lições de um jardim de infância na floresta
} 
comunhão. Somos parte da natureza, e podemos e devemos nos religar a ela (BARBIERI, 2012, p.116).

As intempéries do tempo não impedem que educadores e crianças se dirijam para a escola. Aqui vale destacar a frase "Não existe tempo ruim: a roupa é que é inadequada", trata-se de uma espécie de ditado popular utilizado em países como Alemanha, Dinamarca, Finlândia, Noruega, depreende-se que, pela proximidade entre esses países (localizados ao norte do continente europeu), seja um ditado regional, próprio dos países nórticos.

Ainda nos reportando ao documentário, observamos que o brincar é realizado em pequenos ou grandes grupos, não vimos crianças em momentos mais íntimos, ou isoladas do grande grupo. O desenvolvimento de momentos e brincadeiras conectados com a natureza possibilita que a criatividade e a inovação sejam estimuladas, visto que precisam construir seus objetos de brincar, estruturar suas brincadeiras, exercitar a imaginação, o faz de conta. Sobre o contato físico com a natureza Tuan afirma:

Na vida moderna, o contato físico com o próprio meio ambiente natural é cada vez mais indireto e limitado a ocasiões especiais. (...) O que falta às pessoas nas sociedades avançadas (e os grupos hippies parecem procurar) é o envolvimento suave, inconsciente com o mundo físico, que prevaleceu no passado, quando o ritmo da vida era mais lento e do qual as crianças ainda desfrutavam. (...) A natureza produz sensações deleitáveis à criança, que tem mente aberta, indiferença por si mesma e falta de preocupação pelas regras de beleza definidas. $O$ adulto deve aprender a ser complacente e descuidado como uma criança se quiser desfrutar poliformicamente da natureza. (TUAN, 2012, p. 139 -140)

Propiciar as crianças o contato com a natureza é permitir que ela amplie o seu "ser no mundo", que aprenda a preservar o meio em que vive, que tenha atitudes sustentáveis e conscientes com relação ao meio ambiente.

Louv (2016) ao apresentar uma pesquisa canadense acerca de escolas que possibilitam o contato intenso com a natureza e aponta benefícios:

Os pesquisadores de lá descobriram que as crianças que frenquentam escolas com ambientes naturais diversificados são mais ativas fisicamente, mais conscientes em termos de nutrição, mais civilizadas umas com as outras e mais criativas. A naturalização dos terrenos das escolas resultou em mais envolvimento de adultos e de comunidade próxima. Os pesquisadores canadenses também descobriram que áreas verdes na escola melhoram o aprendizado, em comparação com áreas cimentadas e gramados; que os espaços verdes mais variados para brincar serviam a uma gama mais ampla de alunos e promoviam a inclusão social, independente do gênero, raça, classe ou capacidade intelectual, além de serem mais seguros. (LOUV, 2016, p.235)

Em meio a natureza as crianças podem ser surpreendidas pelas possibilidades que o espaço natural oferece e ainda favorece a estimulação dos sentidos (olfato, tato, paladar, visão e audição), o contato com os quatro elementos da natureza - terra, fogo, água e ar, a aproximação com a fauna e a flora local, a exploração das capacidades e habilidades motoras (subir em árvores, cavando, escalando, correndo, etc), exercícios para a autonomia, socialização. No documentário suíço e em outras produções, depoimentos de pais/responsáveis, profissionais da área da 
educação e saúde evidenciam o contato com a natureza como positivo para a educação e o desenvolvimento das crianças.

\section{DISCUSSÃO}

Nas Escolas da Florestas Norueguesas os fazeres dos educadores são pautados nas vivencias, num fazer intuitivo, não tinham uma proposta pedagógica formalizada, escrita, estudada, e publicada de forma rigorosa. Os motivos que intuitivamente levaram os educadores a enfrentar a floresta é considerarem que a natureza por si só constitui-se no currículo pelo fato de: propiciar a aprendizagem, desenvolver a autonomia, oferecer liberdade, garante um brincar de qualidade, potencializa as relações entre os pares, permite observar a natureza de perto com suas especificidades. (CARRUTHERS, 2010)

As "Ecoescolas" apresentadas por Louv (2016) são escolas projetas e adaptadas para receber elementos da natureza de forma que se tornem escolas com espaços naturais para as crianças, é uma "(...) escola inicialmente projetada e dedicada ao uso dos estudos da natureza como fundamento do currículo". (LOUV, 2016, p.235)

Temos que considerar aqui o contexto econômico, social e político onde essas iniciativas são desenvolvidas, no entanto acreditamos que toda experiência pode ser retratada para outro contexto desde que estejamos atentos as particularidades e necessidades do nosso entorno. Essas experiências peculiares são abordadas por Edwards, Gandini e Forman (1999) quando se referem às escolas da cidade italiana de Reggio Emília:

As escolas em Reggio Emilia não poderiam simplesmente estar em qualquer lugar, e nenhuma delas poderia servir como modelo exato a ser copiado literalmente em outro local. Ainda assim, apresentam características comuns que merecem consideração em escolas de qualquer lugar. (1999, p.157)

Transpor uma experiência, ipsis litteris, não é algo possível e que nem deve ser desejável, mas as inspirações que ela provoca sim, essas são possíveis e podem fazer a diferença. No Brasil podemos identificar semelhanças com o exposto no documentário "Territórios do Brincar" de Renata Meirelles, que retrata a íntima relação das crianças no norte e nordeste brasileiro com a natureza e o brincar. É em meio à natureza e em relação com os pares que essas crianças vivem sua infância, dotadas de muita criatividade, inventividade, habilidade e imaginação.

Diferentemente do documentário europeu, não existe no documentário brasileiro um enfoque educacional, não se pretende mostrar uma concepção de escola para a infância. Meirelles busca tornar visível o brincar como produção cultural das crianças, um brincar genuíno e com extrema conexão com a natureza. No entanto, as brincadeiras e momentos expostos no documentário brasileiro "Territórios do brincar" e àquelas que se observa no documentário londrino são semelhantes, retrata um brincar livre de ações dirigidas, espontâneo, inventivo, cuja única finalidade é brincar, é o brincar pelo brincar. Meirelles, ao falar sobre a criança e a natureza coloca:

Na natureza, as crianças são solicitadas a agir de dentro para fora, pois há apenas sugestões do que, como e por que fazer algo. Ao contrário dos brinquedos prontos, ou da televisão, que já possuem forma, função e conteúdo definidos, os elementos da natureza convidam a criança a agir ativamente no mundo, transformando a matéria a partir de sua imaginação e ação. Assim, de um tronco nasce um carrinho; de um sabugo, uma boneca; de uma folha de bananeira, uma cabana. Ao transformar a matéria-prima, a criança produz cultura. (MEIRELLES, 2016, p.64) 
Nesta perspectiva podemos considerar a possibilidade de conceber a natureza como um espaço educacional, para repensarmos e ressignificarmos os fazeres cotidianos da Educação Infantil, aproximando as crianças da natureza e oferecendo a ela mais do que quatro paredes. Este artigo não busca questionar a qualidade do que desenvolvemos junto com as crianças nos espaços educacionais formais, visa despertar no educador/professor um olhar sensível para o entorno e para a natureza que nos é tão cara nos dias de hoje.

Louv (2016) ao abordar o conceito de "Ecoescolas" relata experiências européias com escolas ar livre e "escola natural", o autor sugere que instituições tradicionalmente construídas cedam espaço para que a natureza adentre e se torne parte integrante de sua antiga estrutura e que possibilite a criação de espaços para brincar em meio à natureza - "naturalizar seus terrenos" (LOUV, 2016, p.234). Desta forma podemos buscar soluções simples, como uma horta, um canteiro de flores, uma floreira, alguns vasos espalhados pelos espaços da instituição, passeios ao ar livre, brincadeiras com os pés no chão, brincadeiras com água, lama, argila, terra, areia e outros materiais naturais.

Entendemos as "Escolas da Floresta" como uma realidade possível no contexto em que foi idealizada, o que ela nos oferece é a certeza de que a conexão entre as crianças e a natureza é possível. O brincar retratado no documentário e no livro "Territórios do Brincar" (2016) corrobora com esta percepção e evidencia um brincar se desenvolve genuinamente com base na natureza e nas relações estabelecidas com os pares.

\section{CONCLUSÃO}

As experiências expostas neste artigo expressam uma forma de conhecer e de vivenciar a natureza de uma maneira intensa pelas crianças. Sinaliza que a relação entre o desenvolvimento da criança e os elementos da natureza pode ser estimulado e estruturado, de acordo com a realidade brasileira. Vislumbramos um fazer pedagógico desconectado com as relações de consumo e com os apelos midiáticos; e uma Educação Infantil que estabeleça o equilíbrio entre espaços artificiais e naturais no cotidiano das crianças.

A qualificação do olhar pedagógico é de suma importância para proporcionar as crianças oportunidades e vivências atreladas à natureza, aos materiais naturais e à elementos que possam conectar as crianças com estes espaços simples e ao mesmo tempo ricos em possibilidades significativas para o desenvolvimento infantil.

A natureza como espaço educacional deve ser pensada pelos profissionais de Educação Infantil como uma constante e não como uma excepcionalidade, seja através de vivências extremas ("Escolas da Floresta") ou através de pequenas iniciativas (horta, por exemplo), o importante é não privarmos nossas crianças do contato com a natureza.

\section{REFERÊNCIAS}

BARBIERI, S. Interações: onde está a arte na infância? São Paulo: Blucher, 2012.

CARRUTHERS, E. As experiências das crianças ao ar livre: um sentimento de aventura? In: MOYLES, J. Fundamentos da Educação Infantil: enfrentando o desafio. Porto Alegre: Artmed, 2010.

EDWARDS, C.; GANDINI, L. E FORMAN, G. As cem linguagens da criança: a abordagem de Reggio Emilia na educação da primeira infância/ tradução Dayse Batista. Porto Alegre: Artmed, 1999.

KINNEY, L.; WHARTON, P. Tornando visível a aprendizagem das crianças/ tradução Magda França Lopes. Porto Alegre: Artmed, 2009. 
LOUV, R. A última criança na natureza - resgatando nossas crianças do transtorno de déficit de natureza. 1ed. São Paulo. Ed. Aquariana, 2016.

MEIRELLES, R. Org. TERRITÓRIO DO BRINCAR DIÁLOGO COM ESCOLAS. Territórios do brincar. 2014. Disponível em: http://territoriodobrincar.com.br/wpcontent/uploads/2014/02/Territ\%C3\%B3rio_do_Brincar_-_Di\%C3\%A1logo_com_Escolas-Livro.pdf Acesssado em: 01/06/2016.

TUAN, Y. Topofilia: um estudo da percepção, atitudes e valores do meio ambiente. (Tradução de Lívia de Oliveira). Londrina: Eduel, 2012. 